\title{
Unmanned Parking System using Lab view
}

\author{
https://doi.org/10.3991/ijoe.v14i10.9104 \\ U. Dhanalakshmi $\left.{ }^{\bowtie}\right)$, V. Bindusree, J. Swetha, D. Khalandar Basha \\ Institute of Aeronautical Engineering, Hyderabad, India \\ udattudhana@gmail.com
}

\begin{abstract}
The existing parking system requires manual support for controlling and monitoring vehicles. The motive of this system is to find out appropriate solution of parking related issues in different aspects. The proposed system can be control the vehicle parking system in shopping malls, Theatres, outdoor stadiums etc. The proposed system consists of two levels of parking for vehicles, where each level has limit of 100. In this proposed parking control system IR sensors will detect and count the number of vehicles on arrival and guided to enter into the vacant parking levels accordingly. This system is designed with automatic lighting and fire detection facility.
\end{abstract}

Keywords-IR sensor, Parking System, Automatic lighting.

\section{Introduction}

From past few years the vehicular parking system is controlling and monitoring [4]-[7] manually. Humans use to move physically in the parking [1] area to provide space for the entering and leaving vehicles and also to switch on and off lights in those areas. Today's human being life cycle is busy and they are not following standard system to check for parking spaces. The objective of the proposed system is to control the operation and to monitor the progress of the process itself. With the advancement of new electronic technologies combining with older building techniques.

\section{Proposed System}

The proposed parking system is very efficient which doesn't require manpower, so the system name as Unmanned Parking System. The proposed system consists of two levels of parking system; these two levels are connected to Lab VIEW [3]-[8] myRio software as the main controller for these systems. The parking system is implemented using NI-Lab VIEW [4]-[8]. The target system is myRIO. The different levels of parking system [1] are designed using IR sensors to detect and count the number of vehicles on arrival and guided to enter into the vacant parking levels accordingly. The system basically consists two levels of parking the vehicles, where each level has limit of 100 vehicles. Once the vehicle enters in to the main gate at that time the first IR sensor will detect the vehicle and check the count of the particular level. If the 
level 1 count value is less than 100 then vehicle directed to level (L1). The lights in the level (L1) will switch on. Whenever any vehicle leaves the level (L1) the IR sensor will detect it and opens the exit gate 1 also decreases level 1 count value and opens the gate for further vehicle parking into level (L1). By detecting full count in level1 vehicles will be diverted automatically to enter into next level i.e., level (L2). The IR sensor in level (L2) detects vehicle and starts increasing the level 2 count value for each detection and also lights in level (L2) will switch on. If any vehicle [2] leaves the level (L2) it will be detected by IR sensor at exit gate 2 and gate will be opened. When any one of the exit sensor is detected the main exit gate will be opened and when all level counts becomes zero then automatically main exit gate will be closed. This process can be repeated for number of levels. The parking system is also provided with alert system. Whenever smoke sensor [8] detects fire or smoke then buzzer will ring alerting everyone in the parking area. This proposed parking system [5] is designed with three smoke sensors connected in each level. All the levels entry gates and exit gates are represented with LEDS. Two level parking system is designed using IR sensors [6], Fire sensor and buzzer.

\subsection{Block Diagram}

The block diagram of Unmanned parking system is shown in figure 1.

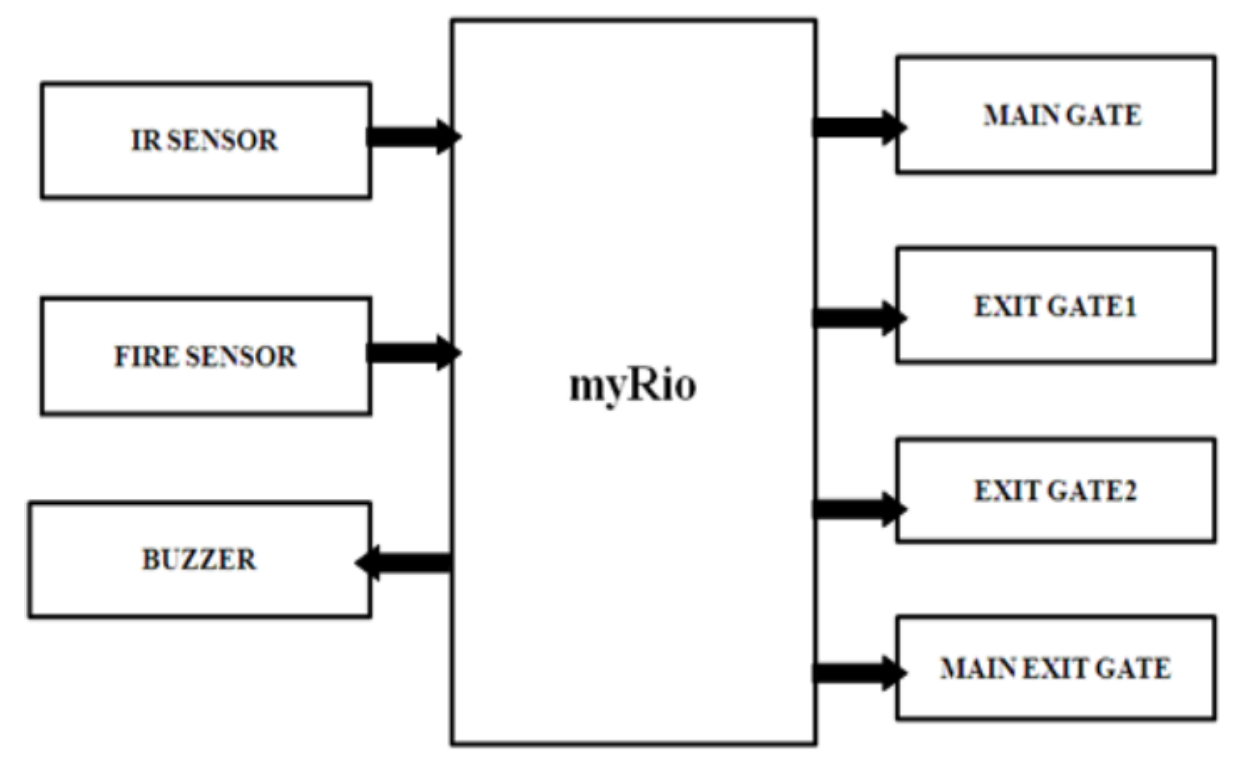

Fig. 1. Unmanned parking system block diagram

\subsection{IR TX and RX}

An infrared sensor is an electronic device which is used to sense light wavelength of its surroundings by either emitting or detecting infrared spectrum. It is also capable 
of measuring the heat being emitted by an object and detecting motion. LED will glow with respect to the IR sensor [6] detection. Every IR sensor has a transmitter and a receiver. Figure 2 shows IR Transmitter \& Receiver. For every transmitter and receiver, there are total two registers and one more register is present to maintain voltage of LED that will show the status of parking slot to customers. When the IR does not detect any object in front of it, it returns the value TRUE, meaning HIGH volt output from the sensor [8] and FALSE for when a object is detected meaning LOW volt output.

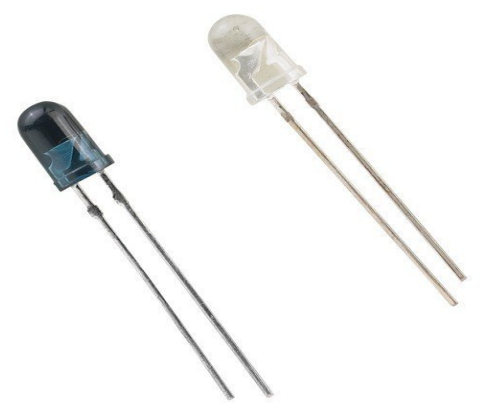

Fig. 2. IR Transmitter \& Receiver

\subsection{Fire sensor}

Fire sensor is used to sense fire generated in various levels of parking system. The fire sensor circuit will be operating at a voltage of $3.3 \mathrm{~V}$ to $5 \mathrm{~V}$ cc. This sensor is capable of detecting fire up to 1 meter distance and the fire source wavelength detection range is $760 \mathrm{~nm}-1100 \mathrm{~nm}$. The sensor circuit consists of a high speed and high sensitive NPN silicon phototransistor and LM393 [6] chipset in comparator. The Analog output pin is interfaced with myRio. The following figure 3 shows Fire sensor.

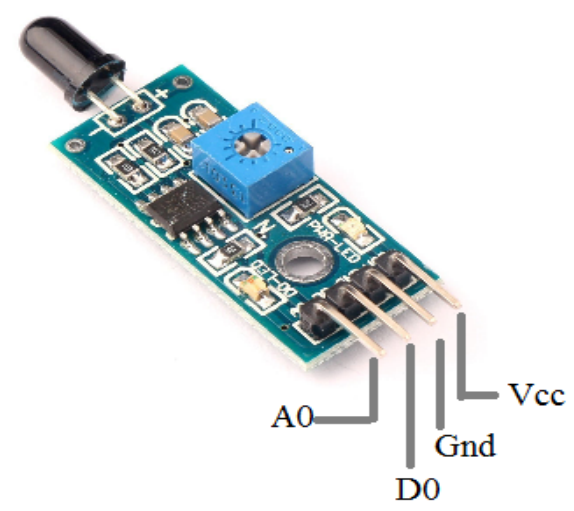

Fig. 3. Fire sensor 


\subsection{Buzzer}

A buzzer is a small compact 2-pin audio signaling device. The longer terminal lead is a positive applied with $6 \mathrm{~V}$ DC. Figure 4 shows buzzer [6]. The shorter terminal lead is a negative typically connected to ground.

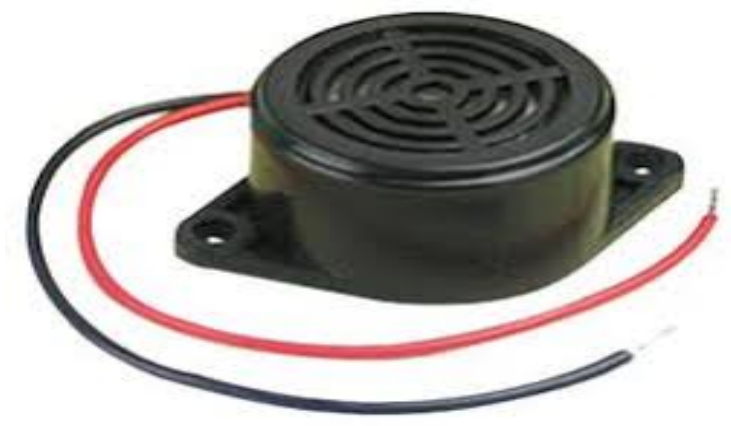

Fig. 4. Buzzer

\section{Interfacing of modules with myRio}

\subsection{Interfacing of IR Sensor}

The proposed parking system consists of 3 IR Sensors; each sensor analog output is connected each sensor output is connected to myRio as shown in figure 5, the Analog Input pins are A/AI0 (pin3), B/AI0 (pin3) and B/AI3 (pin9).

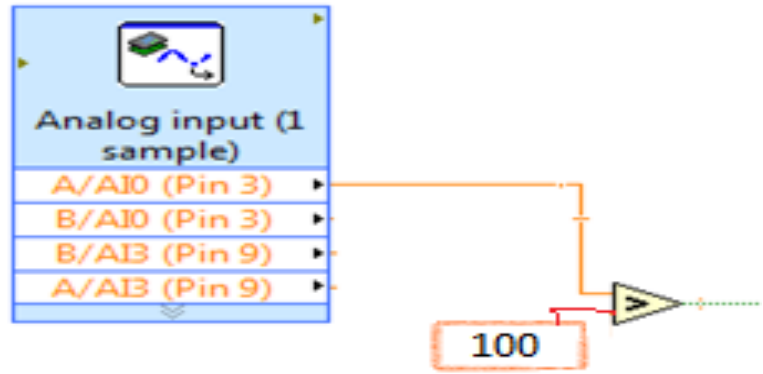

Fig. 5. Interfacing of IR sensor

\subsection{Interfacing of Fire sensor}

The proposed parking system consists of 3 Fire sensors, each sensor analog output is connected to myRio, the Analog Input pins are A/AI3 (pin9), A/AI1 (pin5) and A/AI2 (pin7). 


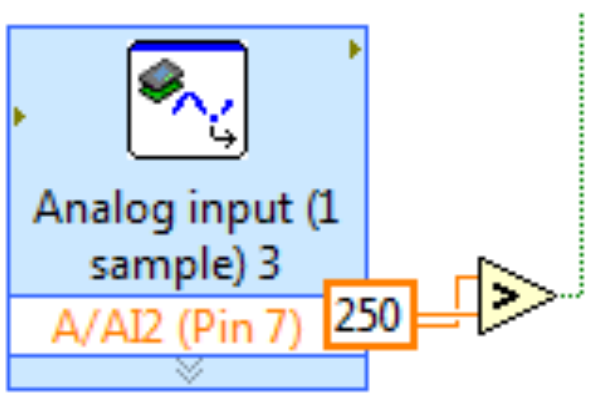

Fig. 6. Interfacing of Fire sensor

Figure 6 shows the interfacing of myRio with Fire sensor.

\subsection{Interfacing of Buzzer}

The proposed parking system consists of 3 buzzers, each sensor output is connected to myRio as shown in figure 7, the Digital Output pins are A/DIO1 (pin13), A/DIO6 (pin23) and A/DIO2 (pin15). The fire sensor output is received by myRio and compared with the threshold value; if the output is greater than threshold then buzzer will ring.

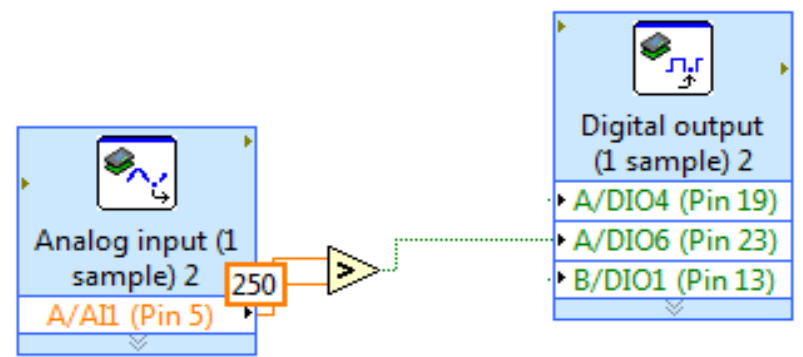

Fig. 7. Interfacing of Buzzer

\subsection{Interfacing of LED}

The proposed parking system consists of 2 LED's; each LED is connected to myRio as shown in figure 8, the Digital Output pins are B/DIO1 (pin13) and B/DIO0 (pin11). 


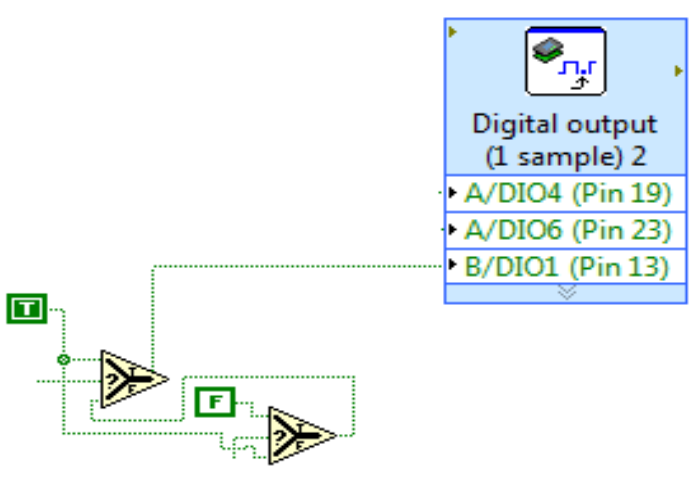

Fig. 8. Interfacing of LED

\section{$4 \quad$ Proposed system Description}

The figure 9 shows proposed unmanned parking system using Lab view myRio [3] consists of IR sensors [6], Fire sensor [6] and buzzer. The system consists of two levels of parking each with limit of 100 vehicles. On detection of every vehicle [2] level count gets incremented, if the count value is less than 100 then the vehicle is directed in to that level for parking [1]. If any vehicle leaves the parking area then exit gate will be opened and level count is decreased.

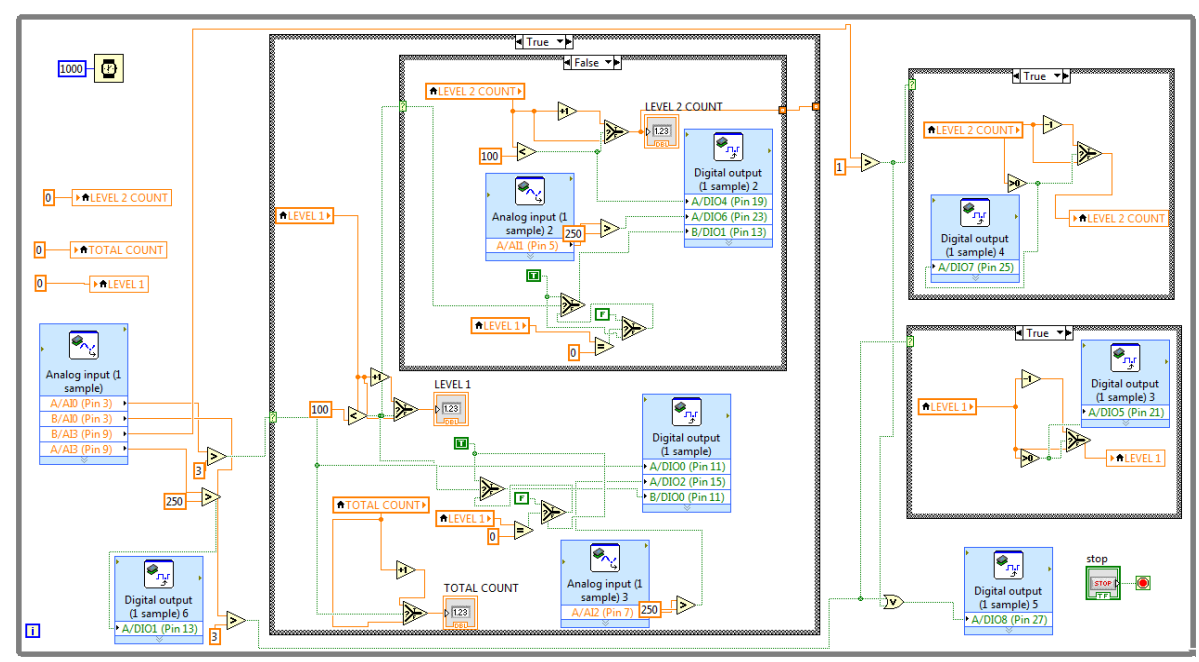

Fig. 9. Block diagram of un manned parking system 


\section{$5 \quad$ Result}

After the successful connection, the data from sensors are sent to Lab view for monitoring of the system. The figure 10 shows the Front Panel of Unmanned Parking System, which provides monitoring [7] and controlling of vehicles in parking system [2] in shopping malls, theatres, outdoor stadiums etc.

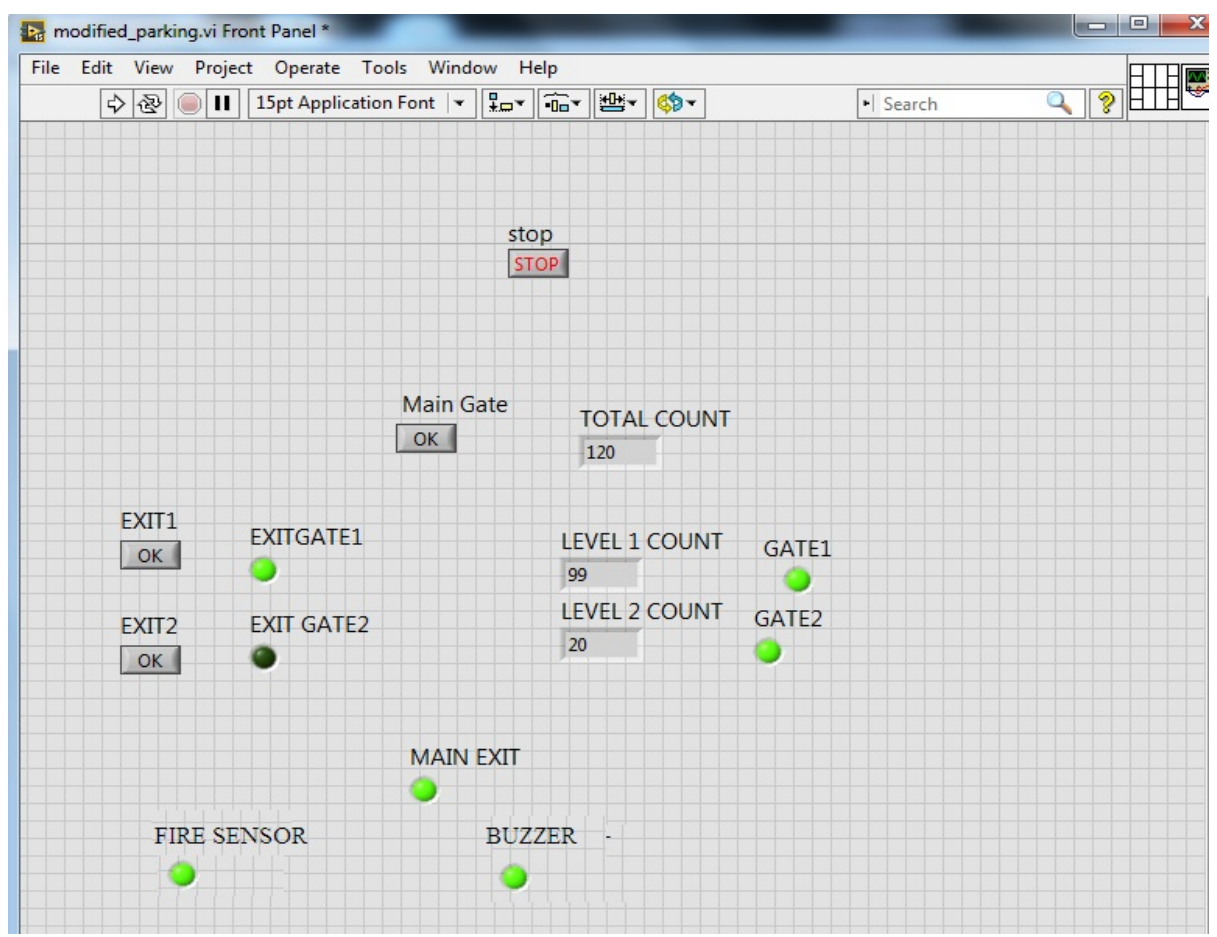

Fig. 10.Front panel of Un manned parking system

\section{Conclusion}

The proposed system is designed for two levels of parking each with 100 vehicles. The number of levels and the number of vehicles can be further extended depending on requirement. This system can be extended to generate automatic bill depending on vehicle entry and exit time, used for malls, theatres etc. When fire is detected using fire sensor, the GSM technique can be used to send messages to police and fire engine people for rescue operation. 


\section{$7 \quad$ Acknowledgements}

The author would like to thank the management, Director, Principal, Head of Department of Institute of aeronautical college, Hyderabad for their support and guidance in completion of this research paper.

\section{References}

[1] R.S.Harishraghav, G.Sri Naga Chaitanya." Advanced Embedded Automatic Car Parking System", The International Journal of Engineering and Science (IJES), vol 3, pp.84-98, 2014.

[2] Hitesh J. Lad, Dr. Vibhuti G. Joshi." Vehicle Parking Management Using Embedded System”, International Journal of Engineering Science and Innovative Technology (IJESIT) Vol 2, Issue 4, July 2013.

[3] Shamili A.R, Lakshmi Ravi Teja M, Nehru. K, Abhinaya. R. "Designing of Scientific Calculator with Case Structure Using NI Labview Software", Journal on Software Engineering. Jan-Mar2017, Vol. 11 Issue 3, p19-30. 12p.

[4] Basil Hamed." Design \& Implementation of Smart House Control Using LabVIEW”, International Journal of Soft Computing and Engineering (IJSCE) ISSN: 2231-2307, Volume-1, Issue-6, January 2012.

[5] Hitendra G. Wasnik, Dr. R. D. Askhedkar, Dr. S.K. Choudhary," Optimal Automatic Car Parking System for Indian Environment”, Indian Streams Research Journal, ISSN:-22307850, Vol.1, pp. 1-4. Nov 11.

[6] Ummadisetty Nagamani, Bindusree V, J Swetha." Wireless Sensor Based Smart Kitchen Monitoring System With Web Server And Internet Of Things", Journal of Advanced Research in Dynamical and Control Systems Vol. 9, Issue 4, Oct.2017.

[7] Vijaykumar G, Anil Gantala, Mary Swarna Latha Gade, P Anjaneyulu, Sk. Hasane Ahammad, "Microcontroller Based Heartbeat Monitoring and Display on PC", Journal of Advanced Research in Dynamical and Control Systems, Vol. 9, Issue 4, 2017. (ISSN: 1943-023X, Scopus Indexed).

[8] Nagarjuna Telagam, Nehru Kandasamy, Menakadevi Nanjundan."Smart sensor network based high quality air pollution monitoring system using Labview. Innovative Journal Of online Education - Vol. 13, No. 8, 2017

\section{Authors}

U. Dhanalakshmi (corresponding author) is with the Electronics and Communication Engineering Department, Institute of Aeronautical Engineering, Hyderabad, India. Currently, she is working as an Assistant Professor. She received her Bachelor degree from JNTUH University/CVSR College of Engineering in 2008. She received her Master degree from JNTUH University/ Nishitha College of Engineering in 2013. She has 4 years of experience in teaching and research.

V. Bindusree is with the Electronics and Communication Engineering Department, Institute of Aeronautical Engineering, Hyderabad, India. Currently, she is working as an Assistant Professor. She received her Bachelor degree from JNTUH Univer- 
sity/Sri Saradhi institute of Engineering and Technology in 2006. She received her Master degree from JNTUH University/ Indur Institute of Engineering and Technology in 2012. She has 4 years of experience in teaching and research.

J. Swetha is with the Electronics and Communication Engineering Department, Institute of Aeronautical Engineering, Hyderabad, India. Currently, she is working as an Assistant Professor. She received her Bachelor degree from JNTUH University/ Tirumala Engineering College in 2012. She received her Master degree from JNTUH University/CMR College of Engineering and Technology in 2016. She has 1 year of teaching experience.

D. Khalandar Basha is with the Electronics and Communication Engineering Department, Institute of Aeronautical Engineering, Hyderabad, India. Currently, he is working as an Assistant Professor. He is interested in the areas of Digital Image Processing, Very Large Scale Integration. He is pursing his Ph.D at Sri Venkateswara University, Tirupati.

Article submitted 26 June 2018. Resubmitted 23 July 2018. Final acceptance 03 September 2018. Final version published as submitted by the authors. 